\title{
Experiences of Social Inclusion and Exclusion During Professional Entry: A Case of Women Teachers in Nepal
}

\author{
Laxmi Paudyal* \\ Kathmandu, Nepal
}

\begin{abstract}
To enter the teaching profession, apart from basic requirements set by the government, there are many other 'rules of the game' and 'open secret criteria' determining who gets included or excluded from being a teacher. The culture of aafnojat (person from own caste) and aafnomanchhe (own relatives) are found to be the most prominent ones. In this paper, I discuss that the issue of inclusion and exclusion is contextual in case of women teachers. Furthermore, the woman from elite group (near and dear of power holders and aafnojat) are getting benefits from the affirmative policy. The ideology of caste as a dominant factor of exclusion is sidelined when the interplay of power of position gets activated and other factors like powerlessness, unmarried status, non-local status, and disability greatly influence the issue of inclusion and exclusion to getinto the teaching job. Hence, the existing generic knowledge that some specific caste groups are always more powerful than others is not the ground reality.
\end{abstract}

Keywords: Social inclusion/exclusion, women teachers, dialogical interview

\section{Context of the Paper}

Nepal has two schooling systems: community and private. The community schools run from the government's supports whereas individuals, groups of individuals and private institutions manage the private ones. Both types of schools are guided by Education Act (1972) and Education Regulation of Nepal (2002). The paper is based on the information generated through qualitative research within the core principle of critical ethnography ${ }^{1}$. Six community schools of Kathmandu, Lalitpur and Kavre were my research sites and twenty-one women teachers of those schools were the main research participants. Dialogical interview ${ }^{2}$ (Kvale, 2005) was conducted with twenty-one women teachers, head teachers, members of School Management Committees (SMCs), men teachers, students, and family members of women teachers. Among twenty-one women teachers whom I 
first dialogued, I selected ten women teachers as core research participants for the second round of interview. Those ten research participants were selected for the second round of dialogical interview because they were interested in this research process and wanted to continue further. Out of ten women teachers, three were dalits, two were from ethnic minority and five were Brahmans/Chhetris; five were from urban and five from rural community schools; eight were married and two were unmarried; and eight were local and two were non-local. In terms of age, they spanned from 25 to 53 years. By teaching status, four women teachers were permanent and six were temporary. Among the temporary, three were from the temporary quota, and three were from the rahat (relief) ${ }^{3}$ quota. They had four to thirty three years of teaching experience, and had the academic qualifications from School Leaving Certificate to Master's degree. None of the women teachers studied in private schools duringtheir schooling. These diverse backgrounds of women teachers contributed to generate the multiple and contextual experiences and showed that they made aheterogeneous group. Further, I also talked with the field level and central level education officials in order to have policy perspective regarding the appointment procedure of teachers, particularly the women teachers. The main field research was carried out in two phases during the period from 2010 to 2012.

\section{Context of Women Inclusion in Teaching Profession}

According to Abraham and Puri (2004), inclusion is an attitude, a value and belief, and a set of actions. The word inclusion implies being a part of something, being embraced into a whole and exclusion means to keep out, to bar, or to expel (p. 13). Social exclusion describes a process by which certain groups are discriminated on the basis of their gender, caste, ethnicity, race, religion, sexual orientation and things like this (Department of International Development [DFID], 2005). According to Oppenheim (1998),"social exclusion is a relational term which is really more about social processes that produce loss of status, power, self-esteem, and expectations" (as cited in Preece, 2000, p. 3). These outcomes are brought about by exclusion from systems. Moreover, attitudes, values and belief of people are seen as key factors in reinforcing their non-participation. Deem (1996) explained that social exclusion and inclusion as well as power are closely linked. Dominant power systems exclude people with their authority and knowledge (as cited in Preece, 2000). Social inclusion is considered a complementary approach that seeks to bring about system-level institutional reform and policy change to remove inequities in the external environment (Department of International Development \& World Bank [DFID \& WB], 2006). It can be one of the strong strategies to ensure social equity, gender parity and to combat social exclusion. In the context of Nepal, the practices of social inclusion and exclusion have been prevalent and observed in various ways historically. However, it has gained prominence in public discourse only after the issue of inclusion was incorporated in "the targeted programs", which was one of the four pillars in Nepal's Tenth Plan (DFID 
\& WB, 2006). The Three Year Interim Plan (2007-2010) was one of the initiatives which was formulated and implemented soon after the Peoples' Movement in 2006 that regarded the issue of inclusion as one of the seven strategic pillars in the plan. Under the heading of Social Justice, the social inclusion was given the highest priority in the plan. These plans considered inclusion as a primary policy concern and inclusive education as a central approach to reduce gender, ethnic, and caste related disparities.

In the context of education, Millennium Development Goals (MDG) [2000] provides a vital roadmap for promoting gender equality and empowering women. One of the goals of Education For All (EFA) is to achieve gender equality in education by 2015. Of the seven themes of EFA National Plan of Action, ensuring social equity and gender parity is one. Similarly, for effective implementation of School Sector Reform Plan (SSRP) [20092015], one of the strategies mentioned is ensuring equity and social inclusion (MOE, 2009). There is an Inclusion Section in the Department of Education. However, it mainly focuses on disability based exclusion. There is also a separate Gender Equality Section which focuses on gender issues. Even SSRP uses the term 'social inclusion' and 'inclusion' interchangeably and focuses only a few protection aspects and numeric inclusion of women teachers (MOE, 2009). Singh (2014) stated that the concepts of social inclusion and exclusion are not well defined, and especially in education contexts, some have limited it todisability and while others have included various other categories like caste, class, religion, patriarchy as well. This is true in case of Nepal also. Although social inclusion has gained prominence in public discourse, as pointed out above (DFID \& WB, 2006), there is lack of clarity, understanding and consistent views about this in general and in education sector in Nepal in particular.

With regard to women in teaching profession, Ganga Bai was among the first known women teachers of Nepal who started the Praramvik Sikchhya (early education) for girls in 1923 in Kanya Pathsala (Girl school) (Sharma, 1986). However, systematic efforts in women education and conceptualizing the importance of women teachers were initiated only after 1970s. Along this line, Equal Access of Women to Education Project (EAWEP) was established in 1971 with an objective to increase the number of women teachers in order to increase girls' access to education (Department Of Education [DOE], 2005). In 1975, as a part ofthe Fifth Five Year Plan (1975 -1980), the government launched an academic upgrading program for girls. The idea was to provide a secondary level education and ten month-teachers' training to girls who were expected to go back to their villages to serve as teachers (Bista, 2006). Similarly, Educational Regulation 1992 made a provision for at least one of the primary teacher positions reserved for a woman teacher (Niraula, 2001). Likewise, Education Act 2001 introduced the provision of at least one woman teacher in each primary school. Moreover, Education Regulation 1992, Third Amendment 2004 states the presence of women teachers in a ratio basis: at least one woman teacher with three teachers; at least two women teachers with seven teachers; and at least three 
women teachers in a school with more than seven teachers (DOE, 2007). The latest policy provision is "making teaching profession inclusive" where reservation is for 33\% women's teachers (Teacher Service Commission Regulation 2002, Fifth Amendment 2010). In the past, the importance of women teachers in school and rationale for recruitment of them in teaching profession werelinked with the girls' enrolment and retention in school, and to perform the nurturing role for younger children (Parajuli, 1995; Bista, 2006). This idea is still there.

Looking at the change in proportion of women teachers, they constituted a bare 8 percent of the teaching force in the entire school system in 1980, and 24 percent in 2003. At the primary level, women teachers occupied 10 percent in 1980 and 29 percent in 2003 (Bista, 2006). In 2014, the percentages of women teachers at primary, lower secondary and secondary level were 42, 28 and 17 respectively (Ministry of Education [MOE], 2014). This shows that women representation in teaching force has gradually improved but is still far less. Moreover, 27 percent of primary schools are without a woman teacher (DOE, 2012). In spite of various national and international efforts and policies, current status indicates that implementation of these policies remain questionable. The current figures also indicate the gender disparity and disparity among women in teaching profession.

Hence, inclusion of women in teaching profession is not satisfactory even after the efforts of forty years. Womenare still facing problems of inclusion and equality. Dimensions of the problems related to the social exclusion of women in teaching profession are in many different forms. Most of the efforts from past to present have been based on Head Counting Approach $^{4}$ (HCA). The quantitative representation of women teachers in school does not necessarily mean that the issues of social exclusion of women teachers are addressed. On the one hand, existing policy and implementation approaches are superficial to address the deep rooted socio-cultural practices, power relation, and stereotype gender division of roles. And on the other hand, due to socialization process in the patriarchy culture, women teachers themselves are not well prepared and are not capacitated enough to deal with the problems they face during entry into their professional world. Except a few project based initiatives like Teacher Education Project (TEP) $2002-2009$, there is no specific capacity building and any strategic program for women to make their meaningful inclusion in teaching profession and enhance their professional efficacy in their professional world. As stated above, there is no consistent view on social inclusion in SSRP; there is structural confusion, for example, separate section of inclusive education, gender equality section in DOE; and focus only on quantitative representation of women in teaching profession at the primary level, these all happened due to a lack of clarity on social inclusion agenda in Nepal. All these have been making inclusion of women in teaching profession a complex process. Given such a situation, we cannot achieve our goal of inclusive and egalitarian society where men and women teachers get equal respect, live with dignity, and develop prosperous society. 
60 L. Paudyal

\section{Women Teachers'Experiences of Social Inclusion and Exclusion During Entry}

This section presents the experiences of women teachers ofsocial inclusion and exclusion during entry in the teaching profession. Experiences of women teachers indicate that a person is not always included or excluded. Various aspects, such as position power, communal affiliation and aspects like these create situations for woman teachers to be included or excluded (Table 1).

Table 1

Factors of Social Inclusion and Exclusion During Entry Into Teaching

Factors of social inclusion during entry

Factors of social exclusion during entry

- $\quad$ Position power and nepotism

- Powerlessness

- Communal affiliation/identity

- Non local status

- Being a local, volunteer contribution

- Supportive family

- Dalit woman

- Married status

- Disabled woman

- Personal determination

- Unmarried status

- $\quad$ Less experience/new in school

Position power and nepotism supported most of the women teachers to access information about job vacancies of teacher positions. A woman teacher of Kavre said that her sister was a DEO staff and her sister played an important role in sharing information about where to apply and how to get the job. Similarly, a woman teacher of Lalitpur got the teaching job through direct appointment letter from DEO. Having a political leader as her relative, a woman teacher of Kavre was supported to bring a rahat quota from DEO and find the school to apply. Madhu ${ }^{6}$ and Lachhi, women teachers of Kathmandu and Kavre respectively, shared that their father and father-in-law were chairpersons of School Management Committee (SMC); they supported Madhu and Lachhi to know about the vacancy and get the job. Madhu, who started teaching in 1984 in Chitwan and is teaching in Kathmandunow, shared "There was a system to appoint women teachers in schools. There were not many educated women in our village. My father was the chairperson of the school, so I easily got the job in the school". Similarly, Lachhi and Shushila, women teachers from Kavre did not get much hurdle to get into the teaching job as their fatherin-laws were chairperson and member in the SMC respectively. This does not mean that these women teachers got the job only based on position power and nepotism. They had basic requirements needed for a teacher, however, position power and nepotism played the central role for getting the job. Hawkesworth (2006) argued that conservative affirmative action merely seeks to change the racial and gender composition of the elite. My findings tell that affirmative policy provision provided more benefits to the women from elite group. Here, elite does not mean higher class and caste, however, those who are near 
and dear of power holders. The findings of my research were very similar to Teas (1993) who noted that factors like 'household gatekeepers' i.e. support from family and 'outside gatekeepers' i.e. connection with power-holder affect women's participation in teaching and training in Nepal. Not only the women in teaching profession, my 22 years of experiences in development sector tell me that many people who are in position power use their position power to include or exclude people while offering jobs and various opportunities. Sometimes, they interpret and manipulate the policy based on their own interest.

These situations are similar to monopoly paradigm of social exclusion where a powerful group, often with distinctive cultural and institutional identities, monopolizes the advantages by closing off the opportunities through the process of "social closures" (Silver, 1995). In a school of Kavre, while two local women teachers, who taught as volunteers for two years, were appointed on the condition that they will be getting only half the salary of the primary school teacher's salary scale, an outsider woman, who brought two rahat quotas, got full scale of primary school teacher's salary. In this case, I found, position power is stronger than local status. One of my friends who is working in the development sector expressed his dissatisfaction that a person is getting more money as monthly salary than others in the same level and with similar responsibilities because of the personal connection with the person who decides the basic salary scale in the organization. It shows that social inclusion and exclusion are contextual and various rules of the game apply in decidingwho gets more or less benefits. Moreover, exclusion also entails the interplay of class, status and power (Silver, 1995).

Likewise, communal affiliation plays an important role in the social inclusion practices. Pari, a woman teacher from Kavre, got the information and job because of communal affiliations and political relations. In the catchment area of this school, about ninety percent of the population was of Tamang/Lama. The political leader who brought the teacher quota from DEO, chairperson of SMC and Pari were from the same Lama community and they supported Pari to get the job. However, the head teacher was from a different community i.e., Brahman. According to Pari,

When I came to this school to inquire, the head teacher told me that they already had a woman teacher, whom they were considering to continue. However, I applied for the position. Sabina (non-Lama) and I had similar marks but I was selected through interview.

In this case, communal affiliation and nepotism/ position power worked for Pari to get the job. But Sabina, who neither had community back up nor could bring therahat quota, was excluded from getting the job. Similar incident had happened in the selection of office helper in that school. A man teacher, who came from the Tarai (the southern plains of the country) to teach in this school, said,

Most of the SMC members and Tamang people said we have to appoint office helper 
62 L. Paudyal

from hamrojat (our community). The former office helper (Brahman man) was asked to leave and then they appointed an office helper from the Lama community. He is a relative of the SMC's chairperson. They would have never kept me if they had their own person who could teach Mathematics.

Similar type of discrimination was also found while recruiting teachers in a school of Kathmandu. Such incidents tell us that communal affiliation was one of the reasons to get opportunity in teaching. Relaxed selection process of teachers at the local level gave the opportunity to someone andat the same time others thus got rejected. It shows that communal affiliation, position power, nepotism and factors like these play a vital role in informing about vacancy, process for application and getting the job.

Like Pari, Rekha, from Lalitpur, experienced both inclusion and exclusion when she joined as a teacher in a government school. As her sister was a DEO staff in an influential position, the DEO directly sent her letter of appointment to the school. However, SMC, teachers and community people did not easily accept her because she was new and a dalit and was appointed directly from the DEO. Rekha said,

Disapproval came from both teachers and community. Community people said as damaikochhori le sametjagirpayo (daughter of a tailor/lower caste also got the job), our (Brahman, Chhetri, Newar...) sons, daughters are unemployed. It felt like an earthquake when I got the job in Jaluka.

The situation provided anavenue to exercise the power game at the local level, too. The quota of lower secondary level teacher brought by Rekha was taken by the head teacher and she was assigned primary level duties. Here, Rekha was takeninto teaching because of the relational aspect. However, she was excluded from getting the position of lower secondary level. As perceived by Haan (1995) here, Rekha was included and excluded at the same time. Moreover, she experienced multiple exclusions (Rodgers, 1995, as cited in Jackson, 1999) being a new teacher, a dalit and a woman.

Likewise, Muna from Kavre also experienced both inclusion and exclusion. She got the job as being a local and acknowledging her volunteer contribution to school. However, she experienced exclusion onher first attempt at theteaching job at another school. People can be excluded in some areas while being included in others (Haan, 1999) was applicable for her. She said,

After passing the SLC, there was a vacancy at Kalika School, and I applied for it. A Brahman woman and I were selected for the final round. The committee said that the other woman should get the job since she was financially poorer than I was. But there was no difference.

Muna heard that the people who were in the selection team from the non-dalit communities questioned, "How could we join hand with a dalit woman as a teacher?" This shows that stereotyped attitude of people regarding dalits have been abolished in 
documents but attitude has not been eliminated (Jackson, 1999). Muna and Rekha faced both gender and caste based exclusion. Dalit women experience endemic gender and caste discrimination and violence (Aloysius, Jayshree, \& Joel, 2006). The dalit women teachers are discriminated and less represented in teaching profession. Out of total teachers, only three percent at primary, two percent at lower secondary, four percent at secondary and less than one percent at higher secondary level are women teachers from dalit community in Nepal (MOE, 2011). This figure is much below compared to their proportionate population which indicates the disparity among women in the teaching profession.

This research found the social exclusion based on marital status as well. The head teacher of ThumkaSchool of Kavre said, "The woman, who competed with Kabita, was equally capable. We appointed Kabita because, if the other woman got married and left the locality, that would hamper the activities of the school." Jackson (1999) pointed out that gender becomes a form of exclusion. Here, within the same gender, unmarried status became the basis for exclusion. Muna and Pragati, both unmarried, had grievances. Pragati said, "While getting recruitment married women are preferred. It is a kind of discrimination . "Sincemarital status is not included in the education policy,theinterpretation of policy was found as per the convenience at the local level. This practice tends to discriminate some groups and favor others.

Looking at individual interests, social inclusion is not always good (Jackson, 1999). Sometimes societal inclusion itself may be exclusionary (Woodward \& Kohil, 2001, as cited in Silver, 2007). This was true in the case of Saru, a woman teacher of Lalitpur. She worked in Land Reform Office and her husband worked in Agriculture Research Centre in Kathmandu. Due to difficulty in commuting daily from home i.e., Dhapakhel to office in Kathmandu, they stayed together in a rented house. When her husband was transferred outside the Kathmandu valley, she had only two options given by her husband: either to leave the existing job or join teaching in a village school. Saru shared,she did not like to quitthe job of Land Reform office because it was a stress free job; she could get more sunbath, knitting sweaters and get more personal time. However, socio-cultural barrier did not allow her to stay alone outside home. Then, she quit the job that she liked and started teaching. The findings showthat rather than their wish and interest,socio-cultural boundary like no decision making role to determine their life, education, participation in patriarchy culture, status quo and aspects like these confined and directed the educational and professional direction of these women teachers.

Further, Pragati, a visually impaired teacher from Kathmandu, had an experience of exclusion while she first attempted ata teaching position. She said, "I attended the whole process, but was not selected. They said to us that blind cannot even check the homework." She again applied for a teaching position at another school. Ten disabled people were in the competition. Pragati said, "I was selected on the quota for the blind; otherwise I would not have been selected. Management favored a local man. I got this because the local 
man candidate was old. " Disabled teachers experienced difficulties both in entering and continuing the profession (Powney et al., 2003). It is obvious that women with disabilities are in double discrimination based on gender and disability (Rousso, 2003). Moreover, the women with disability in developing countries face a triple discrimination due to their disability, gender and developing world status (Thomas \& Thomas, n.d.). Hence, the findings of these studies were very similar to my research findings. It provides that, in spite of the non-discriminatory policy, behavior of people was discriminatory based on physical ability. Nevertheless, affirmative policy has contributed to reduce exclusion.

Contrary to the findings of Bista (2004) who noted family reluctance to permit women to join the teaching profession and that of Teas (1993) who noted that parents did not want their daughters work as teachers due to possible reallocation, my research found that in most of the cases families encouraged women for teaching profession. Upama from Kathmandu did not experience exclusionary behavior from her family or school during entry into teaching. She said, "One of my relatives informed me about the vacancy for a teaching position. I applied for it, passed the competition exam and got selected." Upama's family, especially her mother encouraged her to join teaching in her village school where she had studied.Kala, Muna, Rekha, and Kabita also received encouragement from their families. It shows that families and relatives play a vital role in informing about vacancy, processing application and getting the job.

Albelushi (2004), in a research conducted in Oman, foundteaching to beregarded compatible profession with domesticity. Parents put in minds that their daughters can either become a teacher or a doctor. There is a very strong association between teaching as a profession and traditional gender roles that align themselves with women's long held responsibilities in the domestic sphere (Commonwealth Seretariate \& UNESCO, 2011). The immediate placement and attractive work conditions including the salary, and more free time to spend with children are the motivations for women to become teachers (Albelushi, 2004). Findings from my study and earlier literature from Nepal also supported these findings.

Apart from family supports, personal determination of women was also found to be important aspect for women for getting into teaching jobs. Muna and Shova from Kavre taught for more than one year as volunteers hoping to get regular positions. Kala, Pari and Upama were ready to teach even though the schoolswere far from their homes. In Kala's case, her son, husband, and in-laws were in three different places and she created fourth place for her job. I also found the differences within same caste group. Like, Kabita, a woman teacher from Brahman family of Kavre expressed that she was not allowed to go outside from home to do the job other than teaching. However, Kala, a woman from Brahman family, was staying away from home for the teaching profession. Differences were on education and exposed background of family members. Kala's husband worked in an INGO and other family members were also engaged in various professions. However, 
Kabita's husband was engaged in dairy and householu s mlatıers mn nIs uwn village. These unfoldthat background of the family members, support and encouragement from them, and personal determination made it possible for women's inclusion in the teaching job.

I also found that communal affiliation based on ethnicity played an important role ingetting the teacher's job. In some cases, Brahman men and women were excluded fromthe opportunity of getting the job due to being a minority in the community and less powerful as they had no aafnomanchhe (own person) in the SMC and the DEO. These practices were similar to sovereignty power ${ }^{8}$ of Foucault (Stanthorpe, 2005) and monopoly paradigm of social exclusion where powerful group monopolizes the advantages (Silver, 1995). Here, the social exclusion was neither based on gender nor on patriarchy. The women having relation and affiliation with power holders gotmore benefited from affirmative policy. Caste based exclusion like being dalit was sidelined where position power and communal affiliation became stronger. Initial reservation of SMCs, teachers and people from the non-dalit community to give the appointment as a teacher for a dalit woman did not work as the dalit woman directly came with a letter from the DEO with a rahat quota. However, another dalit and Brahman women who did not see anybody in their favor got excluded fromgetting into the teaching job. Hence, the caste and gender are not the only factors of discrimination and exclusion, butmany other factors determine it. So, the existing generic knowledge as some specific caste groups are always more powerful and others are powerless is misinformed.

\section{Conclusion}

The women teachers experienced both social inclusion and exclusion duringtheir professional entry. Being women teachers, they do not have homogeneous entity and are not always excluded in their professional world. Various aspects collectively affected the women ingettinginto the teaching job. Personal determination hoping for better future played the crucial role in pursuing the job. Socialist feminism perceived women's oppression and exclusion based on patriarchy and gender division of roles. However, this research identified that aspects like position power, communal and political affiliation, married and local status, supportive family, and personal determination contributed for women to get the teaching job. On the contrary, findings also show that status like outsider, unmarried, differently able, dalit, less experienced, and powerless (as not having relatives in power) caused social exclusion while gaining entry into the teaching profession. These aspects of exclusion are not in policies but are found to have been practiced at the local level. Being local and higher caste status was sidelined when position power and communal affiliation came into the centre. All these means that the caste and gender are not the only factors of discrimination and exclusion, there are many other aspects that influence who are included in and who are excluded from theteaching profession. Hence, social exclusion is a very complex phenomenon. 


\section{Notes}

1 Critical ethnography tends to reinforce change (Robertson, 2005). Critical ethnographers contribute to emancipatory knowledge and discourses of social justice (Madison, 2004). They describe, analyze, and open to scrutiny, hidden agenda, power, and assumptions that inhibit, repress and constrain. The critical ethnographers go beyond traditional descriptive form and play the transformative role (Harran, 2006).

2 Dialogical interview is one of the ways that a qualitative researcher talks with people about their experiences and perceptions, where information is generated based on interaction between researcher and research participants. It is a joint endeavor where both parties are searching for true understanding and knowledge (Kvale, 2005).

3 Rahat (relief) quota refers to the temporary teacher quota created to fulfill the increasing demand of teachers. These teachers are distributed based on student teacher ratio.

4 HCA means focus only on numerical increase of women in teaching profession rather than strategic focus on change in traditional gender division of roles at home, and prepare women to take \& effective lead the teaching roles.

5 One of the focus areas of TEP was to increase representation of women and disadvantaged group candidates in teaching by empowering them.

6 The name of women teachers, schools and other people as research participants mentioned in the report are pseudonyms.

7 The social closure refers to the process of subordination whereby one group monopolies advantages by closing off opportunities to outsiders whom it defines as inferior or ineligible.

8 The sovereign power is traditional notion of power where authoritative force acts to control the action of other (Stainthorpe, 2005).

\section{References}

Abrahm, G., \& Puri, M. (2004). Handbook of inclusive education for educators, administrators and planners. New Delhi, India: Sage.

Albelushi, A. (2004). Gender in teacher development: Career choice and commitment in Oman. English Language Teacher Education and Development, 8, 16-27.

Bista, M. B. (2004). A review of research literature on gilrs' education in Nepal. Bangkok, Thailand: UNESCO.

Bista, M. B. (2006). Status of female teachers in Nepal. Kathmandu, Nepal: UNESCO. CommonWealth Secretariat and UNESCO. (2011). Women and the teaching profession: Exploring the feminisation debate. London, England and Paris, France: Authors.

Department of International Development. (2005). Reducing poverty by tackling social exclusion: A policy paper. London, England: Author.

Department of International Development \& World Bank. (2006). Unequal citizens:

Gender, caste and ethnic exclusion in Nepal. Kathmandu, Nepal: Authors.

Department of Education. (2005). Education for all and secondary deucation support program. Bhaktapur, Nepal: Author.

Department of Education. (2007, July). A strategic implmentation plan for gender equality in girls' education. Bhaktapur, Nepal: Author.

Department of Education. (2012). Flash report II. Bhaktapur, Nepal: Author. 
Department of Education. (2013). Flash report I. Bhaktapur, Nepal: Author.

Haan, A. D. (1999). Social exclusion: Towards an holistic understanding of deprivation. London, England: Department for International Development.

Hawkesworth, M. (2006). Feminist inquiry: From political conviction to methodological innovation. New Brunswick, NJ: Rutgers University Press.

Jackson, C. (1999). Social exclusion and gender: Does one size fit all? The European Journal of Development Research, 11, 125-146.

Kvale, S. (2005). The dominance of dialogical interview research. Advance Research Journal, 1-9.

Ministry of Education. (2009). School sector reform plan 2009 - 2015. Kathmandu, Nepal: Author.

Ministry of Education. (2011). Nepal education in figure 2011: At a glance. Kathmandu, Nepal: Author.

Ministry of Education.(2014). Nepal education in figure 2014: At a glance. Kathmandu, Nepal: Author.

National Planning Comission \& United Nations Children's Fund. (1996). Children and women in Nepal. Kathmandu, Nepal: Authors.

Niraula, P. (2001). Literature review: Studies on girls and women education in Nepal. Kathmandu, Nepal: Basic and Primary Education Program II, Danida.

Parajuli, M. N. (1995). Women education program monitoring report. Kathmandu, Nepal: Ministry of Education, Culture and Social Welfare.

Powney, J., Wilson, V., Hall, S., Davidson, J., Kirk, S., \& Edward, S. (2003). Teachers' careers: The impact of age, disability, ethnicity, gender and sextual orientation. Hendon, England: University of Middlesex.

Preece, J. (2000). Challenging the discourses of inclusion and exclusion with off limits curricula. London, England: University of Surrey.

Rousso, H. (2003). Education for all: A gender and disability perspective. Paper commissioned for the EFA Global Monitoring Report 2003/4, The Leap to Equality. Retrieved from http/unesdoc.unesco.org/images/0014/001469/146931e.pdf

Singh, D. (2014). Social inclusion in schools: Experiences and roles of teachers, students, management and parents. Mumbai, India: Tata Institute of Social Sciences.

Silver, H. (1995). Reconceptualizing social disadvantage: Three paradigms of social exclusion. In G. Rodgers, C. Gore, \& J. Figueiredo (Eds.), Social exclusion: Rhetoric, reality, responses (pp. 57-80). Geneva: International Institute for Labor Study.

Silver, H. (2007). The process of social exclusion: The dynamics of an evolving concept. Rhode Island, RI: Department of Sociology, Brown University.

Sharma, G. (1986). Educational history of Nepal. Kathmandu, Nepal: Indu Publishing House.

Stainthorpe, A. (2005). Can Foucault be resisted? A critical consideration of Foucault and 
productive power. Manchester, England: The University of Manchester.

Teas, M. M. (1993). Increasing women's participation in the primary school teaching force and teacher training in Nepal. Washington, DC: World Bank - Policy Research Dissemination Center.

Thomas, M., \& Thomas, M. (n.d.). Status of women with disabilities in South Asia. Manuscript. Retrieved from english.aifo.it/disability/apdrj/selread102/thomas.doc 